\title{
Impact of psoriasis in the quality of life of children, adolescents and their families: a cross-sectional study*
}

\author{
Andac Salman ${ }^{1}$, Ayse Deniz Yucelten ${ }^{1}$, Esra Sarac ${ }^{2}$, Merve Hatun Saricam $^{3}$, Nese Perdahli-Fis ${ }^{4}$
}

DOI: http:/ / dx.doi.org/10.1590/abd1806-4841.20186981

\begin{abstract}
BACKGROUND: Psoriasis is a chronic and inflammatory disease that impairs quality of life and causes psychological symptoms. Despite the high prevalence of psoriasis in pediatric patients, studies investigating the impact of psoriasis in the quality of life of children, adolescents and families are sparse.

OвJестіvе: To investigate the impact of psoriasis in the quality of life of children and adolescents with psoriasis and their families and to determine depression and anxiety levels of the patients.

METHOds: A total of 58 patients with psoriasis aged 7-18 years (median age: 11) and a family member of each patient were included in the study. Children's Dermatology Life Quality Index (CDLQI), Family Dermatology Life Quality Index (FDLQI), Children's Depression Inventory (CDI) and State-Trait Anxiety Inventory for Children (STAIC) were used in the study.

RESULTS: The median PASI score of the patients included in the study was 1.8. The median CDLQI and FDLQI scores in the study groups were 5 and 10, respectively. The median CDI score, STAIC-state and STAIC-trait scores of the patients were 6, 28 and 32.5 , respectively.

StUDY LimitATIONS: Lack of a control group and patient assessment of disease severity. Relatively mild disease severity of the subjects.

Conclusions: Psoriasis has a negative impact in the quality of life of children, adolescents and their families, even in the presence of mild disease. Considering that impairment in quality of life may be associated with psychosocial morbidity, a combined approach with medical therapy, family counseling and quality of life assessment may be beneficial in this patient group.
\end{abstract}

Keywords: Adolescent; Child; Family; Psoriasis; Quality of life

\section{INTRODUCTION}

Psoriasis is a chronic, inflammatory skin disorder affecting approximately $2 \%$ of the population. In almost one third of the patients, the onset of psoriasis is within the first two decades of life. ${ }^{1}$ In addition to signs and symptoms related to cutaneous lesions, psoriasis may cause significant impairment in quality of life and psychological symptoms. ${ }^{2}$ However, despite the high prevalence of psoriasis in childhood, studies investigating the impact of psoriasis in the quality of life of patients and families and psoriasis-related psychosocial morbidity are sparse. Assessment of quality of life in this patient group and their families may be particularly important for the psychological well-being of the children and adolescents. In the long run, such an awareness on the impact of psoriasis in the quality of life of the child and the family may lead to an integration of psychological approach and medical treatment strategies. ${ }^{3}$

\footnotetext{
Received 28 January 2017.

Accepted 06 August 2017.

* Work conducted at the Marmara University School of Medicine, Pendik Research and Training Hospital, Department of Dermatology, Istanbul, Turkey. Financial support: None. Conflict of interest: None.

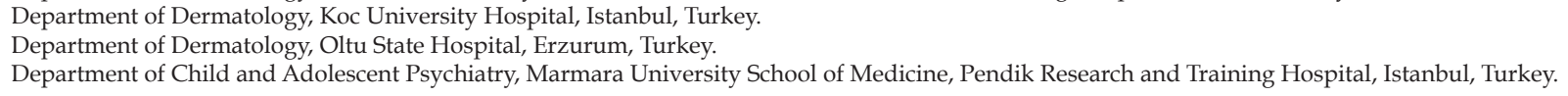




\section{METHODS}

A cross-sectional study was planned to investigate the impact of pediatric psoriasis on depression and anxiety levels of patients and quality of life in patients and their families. Patients with a clinical diagnosis of psoriasis aged 7 to 16 were recruited following an informed consent. Ethical committee approval was obtained prior to subject enrollment (Ethical reference number: B.30.2.MAR.0.01.02/AEK/136).

Patient demographic and disease characteristics were recorded. Psoriasis severity was assessed using Psoriasis Area and Severity Index (PASI). Socio-economic status of the families was assessed using socioeconomic status index (SSI). ${ }^{4}$ According to SSI, families were grouped into five (A, B, C1, C2 and D, in descending order) based on their income, level of education, employment status, occupation, property ownership and possession of objects in the house.

Dermatology related quality of life was assessed using Children's Dermatology Life Quality Index (CDLQI) and Family Dermatology Life Quality Index (FDLQI) in patients and their caregivers, respectively. The CDLQI is a dermatology-specific quality of life instrument consisting of 10 items assessing symptoms and feelings, leisure, school or holidays, personal relationship, sleep and treatment. ${ }^{5} \mathrm{~A}$ score between 0 and 30 is provided and higher scores indicate more impaired quality of life. The FDLQI is a questionnaire developed by Basra and Finlay providing a total score of 0 to 30, higher scores indicating more impaired quality of life. ${ }^{6}$

Depression and anxiety symptoms of the patients were evaluated using Children's Depression Inventory (CDI) and StateTrait Anxiety Inventory for Children (STAIC), respectively.

The CDI is a self-rated, 27-item questionnaire providing a score of 0 to 54 , higher scores suggesting more severe depressive symptoms. A cut-off score of 16 has been recommended for CDI.?

The STAIC consists of 40 items and two parts assessing the levels of state and trait anxiety. ${ }^{8}$ Scores range between 20 and 60 . Higher scores indicate higher levels of anxiety. The validity and reliability of the Turkish versions of indices have been established. ${ }^{9-12}$

\section{Statistical Analysis}

The statistical analysis was done using the Statistical Package for Social Sciences (SPSS Inc., Chicago, Illinois, USA) v17.0. The normality of distribution of variables was assessed using Kolmogorov-Smirnov test. Descriptive data are shown as n (\%) for categorical variables and median (interquartile range) for quantitative variables. Mann-Whitney test and Kruskal-Wallis test were used to analyze differences between independent samples. Spearman's correlation analysis was used for the analysis of the correlations.

\section{RESULTS}

A total of 58 patients ( 32 females, 26 males) with psoriasis were included in the study. The median age of the patients was 11 (9.75-13) years. The median duration of psoriasis was 36 (12-72) months. The median PASI score of the patients was 1.8 (0.9-3.25) at the time of interview. The most common subtypes of psoriasis were localized plaque and generalized plaque psoriasis found in $62.1 \%$ and $22.4 \%$ of the patients, respectively. Family history of psoriasis was present in $20.7 \%$ of the participants (Table 1 ). The most commonly used treatments prior to the interview were topical corticosteroids $(77.6 \%)$, phototherapy $(10.3 \%)$ and acitretin $(6.9 \%)$.

Primary caregiver who filled the FDLQI was mother, father and grandmother in $84.5 \%, 13.8 \%$ and $1.7 \%$ of the patients, respectively.

Socioeconomic status of the patients' families according to SSI were as follows; A (6.9\%), B (15.5\%), C1 (39.7\%), C2 (36.2\%) and $\mathrm{D}(1.7 \%)$.

The median CDLQI score of the patients was 5(2-8.25). According to CDLQI scores, 21 of the patients (36.2\%) have reported a moderate or more effect of psoriasis on their quality-of-life (Table 2). The median FDLQI score of the caregivers was 10(6.75-15.25) (Table 3).

The median CDI, STAIC-state and STAIC-trait scores of the patients were shown in table 3. Only four patients $(6.8 \%)$ had scores higher than 16, the cut-off value in CDI.

When patients were grouped according to their age $(<12$ $(n=32)$ vs $>12(n=26))$, no significant difference was found in terms of median PASI, duration of disease, CDLQI, FDLQI, CDI and STA-

\begin{tabular}{llc}
\hline \multicolumn{2}{c}{ TABLE 1: Demographics of the patients } \\
\hline Characteristics & Median (IQR) \\
\hline Median age (years) & $11(9.75-13)$ \\
Median duration of disease (months) & $36(12-72)$ \\
Median PASI & & $1.8(0.9-3.25)$ \\
& & $\mathbf{n}(\%)$ \\
Sex & Female & $32(55.2 \%)$ \\
Family history & Male & $26(44.8 \%)$ \\
& Present & $12(20.7 \%)$ \\
Psoriasis subtypes & Absent & $46(79.3 \%)$ \\
& Localized plaque & $36(62.1 \%)$ \\
& Generalized plaque & $13(22.4 \%)$ \\
& Guttate & $2(3.4 \%)$ \\
& Palmoplantar & $1(1.7 \%)$ \\
& Scalp & $1(1.7 \%)$ \\
& Nail & $2(3.4 \%)$ \\
& Missing & $3(5.2 \%)$ \\
\hline
\end{tabular}

(IQR: interquartile range)

TABLE 2: Severity of impact on quality of life according to CDLQI scores $(n=58)$

\begin{tabular}{lc} 
CDLQI Score & $\%$ (n) \\
\hline No effect (0-1) & $17.2 \%(10)$ \\
Small effect (2-6) & $46.5 \%(27)$ \\
Moderate effect (7-12) & $24.2 \%(14)$ \\
Very large effect (13-18) & $8.6 \%(5)$ \\
Extremely large effect (19-30) & $3.4 \%(2)$ \\
\hline
\end{tabular}

(CDLQI: Children's Dermatology Life Quality Index) 
IC-trait scores $(p>0.05)$. However, the median STAIC-state scores were significantly higher in patients older than 12 years (26 vs 32, $\mathrm{p}=0.002$ ).

The median duration of disease, PASI and index scores did not differ significantly between socioeconomic status groups $(\mathrm{p}>0.05)$.

The correlations between index scores, patient and disease characteristics were analyzed with Spearman correlation analysis. Age of the patients was positively correlated only with STAIC-state scores ( $r s=.345, \mathrm{p}=.008)$. Duration of the disease was positively correlated with PASI, CDLQI, CDLQI Symptoms and feelings, and FDLQI scores ( $\mathrm{rs}=.400, \mathrm{p}=.002 ; \mathrm{rs}=.289, \mathrm{p}=.029 ; \mathrm{rs}=.269, \mathrm{p}=.043$; $\mathrm{rs}=.300, \mathrm{p}=.023$, respectively). The mean PASI score was positively correlated with CDLQI, CDLQI-Symptoms and feelings, and FDLQI scores ( $r s=.370, p=.004 ; r s=.327, p=.012$, and $r s=.281, p=.033$, respectively).

The CDLQI score was positively correlated with STAIC-state, STAIC-trait and CDI scores ( $\mathrm{rs}=.307, \mathrm{p}=.019$; $\mathrm{rs}=.388$, $\mathrm{p}=.003 ; \mathrm{rs}=.529, \mathrm{p}<.001$, respectively).

When patients were grouped according to CDLQI scores as "small or no effect" (CDLQI score $\leq 6, \mathrm{n}=38$ ) and "moderate or more effect" (CDLQI score $\geq 7, \mathrm{n}=22$ ), PASI, CDI and STAIC-trait scores were significantly higher in the latter group $(p=0.018, p=0.004$, and $\mathrm{p}=0.029$, respectively).

\section{DISCUSSION}

The results of our study indicate that childhood psoriasis causes impairment in quality of life in patients and their families.

Considering the chronic nature of the disease, time-consuming treatments and visibility of lesions by others, psoriasis may influence different aspects of quality of life. Previous studies in adult population have shown that psoriasis may affect major components of an individuals' life such as career choice, education, social relationships and family life., ${ }^{2,13}$ Impairment in quality of life due to psoriasis has been reported to be comparable with major systemic

TABLE 3: Mean scores and percentage of the maximum possible score for CDLQI, FDLQI, STAIC and CDI $(n=58)$

\begin{tabular}{lcc} 
Index & Median (IQR) & \%total \\
\hline CDLQI & $5(2-8.25)$ & $16.6 \%$ \\
CDLQI-Symptoms and feelings & $2(1-2)$ & $33.3 \%$ \\
CDLQI-Leisure & $1(0-3)$ & $11.1 \%$ \\
CDLQI-School or holidays & $0(0-1)$ & $0 \%$ \\
CDLQI-Personal relationships & $0(0-1)$ & $0 \%$ \\
CDLQI-Sleep & $0(0-1)$ & $0 \%$ \\
CDLQI-Treatment & $0(0-1)$ & $0 \%$ \\
FDLQI & $10(6.75-15.25)$ & $33.3 \%$ \\
STAIC-Trait & $32.5(27.75-37)$ & $54.1 \%$ \\
STAIC-State & $28(23-32.25)$ & $46.6 \%$ \\
CDI & $6(3-11.5)$ & $11.1 \%$ \\
\hline
\end{tabular}

(CDLQI: Children's Dermatology Life Quality Index, FDLQI: Family Dermatology Life Quality Index, STAIC: State-Trait Anxiety Inventory for Children, CDI: Children's Depression Inventory, IQR: interquartile range) diseases including arthritis, cancer and coronary artery disease in adult psoriasis patients. ${ }^{14}$

Given the ongoing psychosocial development and lack of adequate coping strategies, patients with psoriasis may experience even more impairment in their quality of life. Moreover, since involvement of caregivers is usually necessary for treatment, the quality of life of children and adolescents' families may also be impaired. Despite the vast amount of studies in adult patients, there is a small number of reports about quality of life in children and adolescents with psoriasis and their families. ${ }^{1,5,15-17}$

Previous studies have shown a negative impact of psoriasis in quality of life. Lewis-Jones and Finlay have reported a mean CDLQI score of 5.4 in 25 patients. ${ }^{5}$ Jager et al. have reported a median CDLQI score of 6 in 39 patients whose mean PASI score was 6.3.15 Similarly, in another study comprising 45 patients, impairment of quality of life was demonstrated with a mean CDLQI score of 5.05. ${ }^{1}$ Beattie and Lewis-Jones have reported a mean CDLQI score of 9.17 in 29 patients. Mean CDLQI scores of psoriasis patients were higher compared with other dermatological conditions such as generalized eczema, urticaria, alopecia, and acne. ${ }^{16}$ Manzoni et al. have also reported that patients with psoriasis had higher CDLQI scores than patients with vitiligo. ${ }^{17}$

Accordingly, with the existing data, although our study population mostly had mild psoriasis, $36.2 \%$ of our patients have reported a moderate or worse impairment of quality of life with a median CDLQI score of 5 . The results of our study indicate that even mild psoriasis can cause impairment in the daily life of patients, thus assessment of quality of life in pediatric psoriasis patients might be beneficial.

Children and adolescents with chronic diseases, including psoriasis, frequently need their caregivers to be involved in disease-related activities, such as doctor visits, and application of treatment. ${ }^{18}$ This relationship warrants the evaluation of families' quality of life in patients with psoriasis in addition to patients' quality of life. A recent study in adult patients with psoriasis showed that $87.8 \%$ of the cohabitants had impaired quality of life according to FDLQI. They also had higher anxiety and depression levels than controls. ${ }^{19}$ Eghlileb et al. have reported that psoriasis in adult patients affects different aspects of partners' and families' lives, such as limitations on daily and leisure activities, social disruption, psychological pressure and deterioration of personal relationships. ${ }^{20}$ In agreement with the published data, we have demonstrated an impaired quality of life of the family members of the patients, confirming the impact of disease on family life. Since parental response to any chronic illness can affect the child's adaptation, interventions such as counseling, especially on stress management and problem solving strategies, will promote better mental health in parents. ${ }^{21}$ This will probably lead to a better family functioning and a better care for their children.

Negative impact of psoriasis on quality of life and psychosocial development may result in psychological maladjustment in several areas. Previous studies in adult and pediatric psoriasis patients have reported a tendency towards high levels of anxiety, depression, stigmatization and low self-esteem. ${ }^{13,18,22}$ However, it has also been documented that not all patients with chronic disorders 
appeared maladjusted. ${ }^{23}$ Psychological adjustment relies on many factors, of which vulnerability and resilience are also important components. In our study the severity of depressive symptoms tended to be low, whereas, adolescent patients in the sample had higher levels of anxiety. For many chronically ill children, anxiety about being physically different from their peers is a common concern. ${ }^{24}$ It becomes even a major issue especially in adolescence. That is, when sense of belonging to a peer group is one of the challenges, and consequently physical appearance becomes an important focus. Therefore, any skin disease may cause a considerable level of psychological distress for the young in this particular age group. ${ }^{5}$

Another finding of the study was that, the group with high impact on quality of life had higher levels of anxiety and depressive symptoms. It can be assumed that there is a bi-directional relation between the patients' sense of quality of life and emotional symptoms. This finding is highly correlated with previous studies emphasizing that as the impact on quality of life becomes greater, the depressive and anxiety symptoms become more prominent. ${ }^{25}$ Although it is not possible to draw definite conclusions due to our study's cross-sectional design, it might be speculated that impairment of quality of life along with the possible stigmatization and social isolation may cause increased levels of psychosocial morbidities in patients with psoriasis.

In our study CDLQI scores were positively correlated with severity and duration of psoriasis, anxiety and depression scores.
Considering that overall severity in our study group was mild, early recognition and assessment of quality of life impairment in patients with psoriasis may prevent them having impaired daily functioning and development of psychiatric morbidities.

In the present study, there was no significant correlation between FDLQI and CDLQI scores. This result indicates that psoriasis may affect the quality of life of families regardless of its effect in the quality of life of patients with psoriasis. Therefore, in addition to patients' quality of life, family quality of life should also be carefully assessed, so that families can provide better care to their children.

Our study is limited by the mild nature of the disease in our study population. Even though an impairment in quality of life was detected, it would be interesting to see the level of quality life impairment between mild and severe disease groups. Other limitations of our study are lack of an age-matched control population and patient assessment of their disease severity.

\section{CONCLUSION}

In conclusion, even mild psoriasis has a negative impact on quality of life in children, adolescents and their families. Considering that difficulties in school, family life and personal relationships during pediatric ages may cause long-term sequelae such as psychiatric morbidities, integration of assessment of quality of life in patients with psoriasis and their families to medical treatments might be beneficial for prevention of invisible effects of psoriasis. $\square$

\section{REFERENCES}

1. Gånemo A, Wahlgren CF, Svensson A. Quality of life and clinical features in Swedish children with psoriasis. Pediatr Dermatol. 2011;28:375-9.

2. Warren RB, Kleyn CE, Gulliver WP. Cumulative life course impairment in psoriasis: patient perception of disease-related impairment throughout the life course. $\mathrm{Br} \mathrm{J}$ Dermatol. 2011:164:1-14.

3. Titman P. The impact of skin disease on children and their families. In: Walker C, Papadopoulos L, editors. Psychodermatology. New York: Cambridge University Press; 2005. p. 89-101.

4. Kalaycıoglu S, Kardam F, Tuzun S, Ulusoy M. Turkiye için bir sosyoekonomik statu olcutu gelistirme yonunde yaklasim ve denemeler. Toplum ve Hekim. 1998;13:126-37

5. Lewis-Jones MS, Finlay AY. The Children's Dermatology Life Quality Index (CDLQI): initial validation and practical use. Br J Dermatol. 1995;132:942-9.

6. Basra MK, Sue-Ho R, Finlay AY. The Family Dermatology Life Quality Index: measuring the secondary impact of skin disease. Br J Dermatol. 2007;156:528-38.

7. Kovacs M. The Children's Depression, Inventory (CDI). Psychopharmacol Bull. 1985:21:995-8.
Spielberger CD. Manual for State-Trait Anxiety Inventory for children. Palo Alto, CA Consulting Psychologists Press; 1983.

9. Didar Balci D, Ö Sangün, Inandi T. Cross Validation of the Turkish Version of Children's Dermatology Life Quality Index. J Turk Acad Dermatol. 2007;1:71402a.

10. Yılmaz 0, Türkeli A, Yüksel $H$. The validity and reliability of the Turkish version of the Family Dermatology Life Quality Index. Symposium of Allergic Diseases and Treatment in Clinical Immunology, 1-4 November, 2011, Antalya, Turkey. Abstract Book; P113. p. 73

11. Oy B. Children's depression inventory: validity and reliability study. Turk Psikiyatri Derg. 1991;2:132-6.

12. Ozusta S. Turkish standardization, reliability and validity of State Trait Anxiety Inventory for children. Turk J Psychol. 1995;10:32-44.

13. Kimball $A B$, Jacobson $C$, Weiss $S$, Vreeland MG, Wu Y. The psychosocial burden of psoriasis. Am J Clin Dermatol. 2005;6:383-92.

14. Rapp SR, Feldman SR, Exum ML, Fleischer AB Jr, Reboussin DM. Psoriasis causes as much disability as other major medical diseases. J Am Acad Dermatol. 1999;41:401-7. 
15. de Jager ME, van de Kerkhof PC, de Jong EM, Seyger MM. A cross-sectional study using the Children's Dermatology Life Quality Index (CDLQI) in childhood psoriasis: negative effect on quality of life and moderate correlation of CDLQI with severity scores. Br J Dermatol. 2010;163:1099-101.

16. Beattie PE, Lewis-Jones MS. A comparative study of impairment of quality of life in children with skin disease and children with other chronic childhood diseases. Br J Dermatol. 2006;155:145-51.

17. Manzoni AP, Pereira RL, Townsend RZ, Weber MB, Nagatomi AR, Cestari TF. Assessment of the quality of life of pediatric patients with the major chronic childhood skin diseases. An Bras Dermatol. 2012;87:361-8.

18. Lin VW. Tough-skinned kids: identifying psychosocial effects of psoriasis and helping pediatric patients and families cope. J Pediatr Nurs. 2012;27:563-72.

19. Martínez-García E, Arias-Santiago S, Valenzuela-Salas I, Garrido-Colmenero C, García-Mellado V, Buendía-Eisman A. Quality of life in persons living with psoriasis patients. J Am Acad Dermatol. 2014;71:302-7.
20. Eghlileb AM, Davies EE, Finlay AY. Psoriasis has a major secondary impact on the lives of family members and partners. Br J Dermatol. 2007;156:1245-50.

21. Williams PD, Williams AR, Graff JC, Hanson S, Stanton A, Hafeman C et al. A community-based intervention for siblings and parents of children with chronic illness or disability: the ISEE study. J Pediatr. 2003;143:386-93.

22. Bilgic A, Bilgic Ö, Akış HK, Eskioğlu F, Kılıç EZ. Psychiatric symptoms and healthrelated quality of life in children and adolescents with psoriasis. Pediatr Dermatol. 2010;27:614-7

23. Boekaerts M, Röder I. Stress, coping, and adjustment in children with a chronic disease: a review of the literature. Disabil Rehabil. 1999;21:311-37.

24. Sandberg S, Stevenson J. Psychiatric Aspects of Somatic Disease. In: Rutter M Bishop D, Pine D, Scott S, Stevenson JS, Taylor EA, Thapar A, editors. Rutter's Child and Adolescent Psychiatry. Oxford: Blackwell Publishing Lt; 2008. p. 930-44.

25. Bilgiç 0, Bilgic A, Bahali K, Bahali AG, Gurkan A, Yilmaz S. Psychiatric symptomatology and health-related quality of life in children and adolescents with alopecia areata. J Eur Acad Dermatol Venereol. 2014;28:1463-8.

\section{AUTHORS'CONTRIBUTIONS}

\section{Andac Salman $\quad$ (iD) ORCID 0000-0002-6407-926X}

Statistical analysis, Approval of the final version of the manuscript, Conception and planning of the study, Elaboration and writing of the manuscript, Obtaining, analyzing and interpreting the data, Effective participation in research orientation, Intellectual participation in propaedeutic and / or therapeutic of cases studied, Critical review of the literature, Critical review of the manuscript

Ayse Deniz Yucelten $\quad$ (iD) ORCID 0000-0002-4251-0581

Approval of the final version of the manuscript, Design and planning of the study, Preparation and writing of the manuscript, Effective participation in research orientation, Critical review of the literature, Critical review of the manuscript

Esra Sarac $\quad$ (iD) ORCID 0000-0002-9870-9733

Approval of the final version of the manuscript, Conception and planning of the study, Effective participation in research orientation

Merve Hatun Saricam $\quad$ (iD) ORCID 0000-0002-9230-2190

Approval of the final version of the manuscript, Conception and planning of the study, Effective participation in research orientation

Nese Perdahli Fis $\quad$ (iD) ORCID 0000-0002-4806-0876

Approval of the final version of the manuscript, Conception and planning of the study, Elaboration and writing of the manuscript, Intellectual participation in propaedeutic and / or therapeutic of cases studied, Critical review of the manuscript

How to cite this article: Salman A, Yucelten AD, Sarac E, Saricam MH, Perdahli-Fis N. Impact of psoriasis in the quality of life of children, adolescents and their families: a cross-sectional study. An Bras Dermatol. 2018;93(6):819-23. 